\title{
Prevalence of Gastrointestinal Nematodes in Sheep at Yabello Town, Borena, Ethiopia
}

\author{
Temesgen Handiso ${ }^{1}$, Beredu Yohannes ${ }^{2}$ and Biruk Alemu ${ }^{3 *}$ \\ ${ }^{1}$ Hwassa University, School of Veterinary Medicine, Ethiopia \\ ${ }^{2}$ Damboya Wereda Livestock and Fisheries Office, Ethiopia \\ ${ }^{3}$ Veterinary Drug and Animal Feed Administration and Control Authority, Ethiopia
}

Submission: April 03, 2019; Published: April 24, 2019

*Corresponding author: Biruk Alemu, Veterinary Drug and Animal Feed administration and control authority, Hawassa, Ethiopia

\begin{abstract}
A cross-sectional study was conducted on 384 black head sheep kept in and around Yabello from November 2016 to May 2017 to estimate the prevalence of gastrointestinal nematode and to assess the degree of infection. The association with risk factors such as- age, sex, treatment history, and body condition were also determined in the current study. Coprological methods including floatation technique and McMaster egg counting techniques were used for screening and counting the eggs of observed gastrointestinal (GIT) nematodes. Out of 384 fecal samples examined in the laboratory, an overall prevalence of $74.7 \%$ nematode infestation was recorded and it indicates 287 sheep harbors at least one genera of nematode out of 384 animals. The study revealed significant association $(\mathrm{P}<0.05)$ within sex and the higher prevalence of nematodes in female animals was recorded compered to males and the higher prevalence of nematodes in untreated sheep than treated ones was recorded with significant association $(\mathrm{P}<0.05)$ between the groups. The prevalence of nematodes had no significant association with other risk factors (body condition and age). The proportion of the study animals infected mildly, moderately and severely were (76.7\%), $(16.0 \%)$ and $(7.3 \%)$ respectively. The majority of examined animal on average had the egg per gram of feces (EPG) less than 800. In conclusion, the study revealed that GIT nematodes were major parasitic infections of black head sheep in the study area. Therefore, effective strategic treatment and public awareness creation should be instituted in the study area.
\end{abstract}

Keywords: Prevalence; Gastrointestinal nematodes; Black-head Sheep; Yabello; Ethiopia

\section{Introduction}

Ethiopia is one of the countries which use the traditional livestock keeping system. The livestock population of the country is estimated to be 52.13 million heads of cattle, 24.2 million heads of sheep, 22.6 million of goats, 0.99 million heads of camels, 8.73 million equines and 48.89 million chickens which have a significant contribution to the national economy. Sheep and goats provide as much as $30 \%$ of the meat and milk consumed in Sub-Saharan Africa and is found on small holdings through the continent [1]. Sales of sheep products are a vital source of cash, especially for smallholders who do not have access to credit or farm income. Their small size, high reproductive capacity, and rapid growth rates make small ruminants a more flexible short term for investment than are cattle [2]. However, this huge potential wealth is untapped to the livelihood of village farmers and contribution to the national economy at large is minimal. The reasons are a preponderance of infectious and parasitic disease, age-old-traditional management system, inferior genetic makeup coupled with under-nutrition and absence of well-developed market infrastructure [3]. Additionally, these species have received much less attention to research and development agencies that have cattle [2].
Stomach and intestinal worms occur in all species of animals. Young and malnourished animals of both sexes and lactating animals are most suitable to these parasites. Stomach worms affect especially camels, goats, and sheep. Different types of worms are transmitted when an animal eats grass or drinks water contaminated with larva or eggs. The problem is especially common in the rainy season [4]. Parasitic diseases remain the main constraint to animal production systems across all agro-ecological zones throughout the world. The productive and reproductive potential of domesticated livestock is adversely impaired by clinical and sub-clinical helminthes diseases. Among helminths, gastrointestinal nematodes significantly affect the production of sheep due to a reduction in appetite, loss of body condition, anemia, hypoproteinemia, impaired digestive absorptive efficiency, other pathogenic complications and even death of animals [5]. Parasitic nematodes of livestock are controlled mainly through anthelmintic treatment. Even with optimally timed, strategic treatments, this type of control is expensive and, in most cases, only partially effective. In addition, the excessive and frequent use of anthelmintics has resulted in substantial and 
widespread problems with anthelminthic resistance in nematode populations [6].

Endoparasites are responsible for the death of one-third of lamb's considerable losses of parts of carcasses condemned during meat inspection [7]. It is well recognized that in resource-poor regions of the world, helminthes infections of sheep and goats are major factors responsible for economic losses through a reduction in productivity and increased mortality [8]. Helminthic infections in the sheep are among serious problem in the developing countries, particularly where nutrition and sanitation standards are generally poor through a reduction in production in infected animals and mortality. Most parasitic helminthes infect their host via the oral route and live either at the mucosal surface of the gastrointestinal tract or cross the mucosal barrier on their way to predilection site. The problem is greater in tropical countries with good rainfall [9]. Internal parasitism is one of the biggest problems in small ruminant animals. Internal parasite infections of herds can cause major health issues, which have a major effect on the animal's performance and cause great economic losses to the producer. In fact, most of the economic losses caused by internal parasitosis are actually not due to mortality but production loss [10]. Although helminthic parasites of sheep livestock are ubiquitous in all of the agro-climatic zones of Ethiopia with prevailing weather conditions that provide a favorable condition for their survival and development, their presence does not mean that they cause overt diseases. Among the diseases that constrain the survival and productivity of sheep, gastrointestinal parasites infection ranks highest on a global index [8].

In Ethiopia helminthes infections in ruminants are characteristically chronic and insidious in nature and have attracted very little attention, including research funds, when compared with viral, bacterial and some protozoan diseases. This is in spite of the fact that they undoubtedly exert a heavy toll on the health and productivity of this vitally important livestock resource, with obvious implications for the rural and national economies of the country $[11,12]$. Even though Ethiopia endowed with a large number of sheep population, little attempts have been made in the past to study the health aspect of these animals. Lack of well-established data on the magnitude, distribution and predisposing factors of black head sheep GIT parasites in the study area initiated the current study. Therefore, the main objectives of the study were:

a. To estimate the prevalence of gastrointestinal nematode parasites in black-head sheep breed in and around Yabello, Borena.

b. To assess the level of infection by GIT nematode parasites of black-head sheep.

\section{Materials and Methodology}

\section{Study Area}

Yabello town is found in Borena, Oromia regional state in southern part of Ethiopia, located at about 565 Kilometers away from Addis Ababa at an elevation of 1000-1650 meters above sea level. Generally, the Borena area represents a vast lowland area of southern Ethiopia covering an area of about 95,000 km2. The area has an average annual rainfall and temperature of 300-700 millimeter and 19-24 degree Centigrade respectively [13].

\section{Study animals}

The study population was black-head sheep in and around Yabelo town. The study animals selected include all age, which was grouped as young and adult, both sexes, recently treated and not treated, and body conditions (poor, medium and good).

\section{Study design}

A cross-sectional study was conducted to estimate the prevalence of GIT nematodes and to asses' degree of infection in black-head sheep through coprological examination. From selected sheep, the information about sex, age, history of treatments and body condition score were recorded carefully. These risk factors were assessed for the presence of a possible association with GIT nematodes occurrence.

\section{Sample size and sampling procedure}

The desired sample size was calculated using the standard formula described by Thrusfield [14] by considering 95\% confidence interval and a $5 \%$ absolute level of precision as follows;

Where, $\mathrm{n}$ = sample size; Pexp= expected prevalence; and $\mathrm{d}=$ desired level of precision (5\%)

Since there was no previous work done in the area, the expected prevalence of $50 \%$ was considered. Accordingly, a total of 384 sheep were selected from the target population for the study.

\section{Study Methodology}

\section{Coprological examination}

Fecal samples were collected directly from the rectum of the study sheep and placed in universal bottles. Then, labeled with all necessary information and transported to Yabello Regional Veterinary Laboratory. The samples were examined by simple floatation and McMaster following the standard procedures described by Soulsby [15] and Urquhart et al. [16]. Positive fecal samples were subjected to McMaster egg counting technique and the degree of infection was categorized based on description by Taylor et al. [17]. The animals were then categorized as lightly, moderately and severely infected according to their EPG counts $[17,18]$. In the laboratory, the samples were processed on the date of collection or stored at $4{ }^{\circ} \mathrm{C}$ until processed. The sample examined under a microscope (10X or 40X) and eggs of the different system of the area was characterized by mixed crop-livestock nematodes which identified on the base of morphological production farming system and the soil type of the area appearance and size of eggs.

\section{Data management and analysis}

All collected data were entered to Microsoft excel sheet and analyzed by using SPSS 20 version software. Descriptive statics 
were used to determine the prevalence of gastrointestinal parasites and X2 test was used to look at the significance of the difference between different factors (sex, age, body conditions, and treatment history).

\section{Results}

\section{Overall prevalence of GIT nematodes}

From 384 fecal samples examined for gastrointestinal nematodes, 287 (74.7\%) of black-head sheep were found infected. The higher prevalence rate was observed in female (77.4\%) than

Table 1: The prevalence of GIT nematodes with the association between categories of the risk factors.

\begin{tabular}{|c|c|c|c|c|c|c|}
\hline \multicolumn{2}{|c|}{ Variables } & No. of sheep Examined & No. of Sheep Positive & Percentage (\%) & $\mathbf{X}^{2}$ & P-value \\
\hline \multirow{2}{*}{ Sex } & Male & 101 & 68 & 67.3 & \multirow{2}{*}{3.99} & \multirow{2}{*}{0.046} \\
\hline & Female & 283 & 219 & 77.4 & & \\
\hline \multirow{2}{*}{ Age } & Young & 120 & 84 & 70 & \multirow{2}{*}{2.08} & \multirow{2}{*}{0.150} \\
\hline & Adult & 264 & 203 & 76.9 & & \\
\hline \multirow{3}{*}{ *BCS } & Good & 160 & 114 & 71.25 & \multirow{3}{*}{1.77} & \multirow{3}{*}{0.412} \\
\hline & Medium & 100 & 77 & 77 & & \\
\hline & Poor & 124 & 96 & 77.4 & & \\
\hline \multirow{2}{*}{ History of Rx } & Non treated & 299 & 258 & 86.3 & \multirow{2}{*}{95.41} & \multirow{2}{*}{0.000} \\
\hline & Treated & 85 & 29 & 34.1 & & \\
\hline \multicolumn{2}{|c|}{ Total } & 384 & 287 & 74.7 & & \\
\hline
\end{tabular}

${ }^{*}$ BCS stands for body condition score

\section{Quantitative examination Results}

Table 2: Mean estimation of egg per gram of feces.

\begin{tabular}{|c|c|c|c|c|c|}
\hline \multicolumn{2}{|c|}{ Variables } & \multirow{2}{*}{$\begin{array}{c}\text { No. of Sheep Examined } \\
258\end{array}$} & \multirow{2}{*}{$\begin{array}{l}\text { Mean } \\
529.3\end{array}$} & \multirow{2}{*}{$\begin{array}{c}\text { Standard Error } \\
22.46\end{array}$} & \multirow{2}{*}{$\begin{array}{c}95 \% \mathrm{Cl} \\
485.0-573.5\end{array}$} \\
\hline & Not treated & & & & \\
\hline treantio & Treated & 29 & 625.9 & 66.71 & $489.2-762.5$ \\
\hline \multirow{2}{*}{ Age } & Young & 84 & 557.7 & 42.83 & $472.5-642.9$ \\
\hline & Adult & 203 & 531.3 & 24.43 & 483.1- 579.4 \\
\hline \multirow{2}{*}{ Sex } & Female & 219 & 520.8 & 23.38 & $474.7-566.8$ \\
\hline & Male & 68 & 597.8 & 48.92 & $500.1-695.4$ \\
\hline \multirow{2}{*}{ *BCS } & Poor & 96 & 874.0 & 47.15 & $780.1-967.9$ \\
\hline & Medium & 77 & 403.1 & 23.82 & $355.8-450.4$ \\
\hline \multicolumn{2}{|c|}{ Overall } & 287 & 539.0 & 21.32 & $497.1-581.0$ \\
\hline
\end{tabular}

*BCS stands for body condition score

Table 3: Mean estimation of egg per gram of feces.

\begin{tabular}{|c|c|c|c|}
\hline $\begin{array}{c}\text { Degree of } \\
\text { Infestation }\end{array}$ & $\begin{array}{c}\text { No. of Sheep } \\
\text { Examined }\end{array}$ & Frequency & Prevalence (\%) \\
\hline Light & 287 & 220 & 76.66 \\
\hline Moderate & 287 & 46 & 16.03 \\
\hline Severe & 287 & 21 & 7.31 \\
\hline Total & 287 & 287 & 100 \\
\hline
\end{tabular}

Positive fecal samples for GIT nematodes were subjected to McMaster egg counting chamber for EPG count to determine the degree of parasitic severity. The majority of positive animals had the EPG count on an average of less than 800 (Table 2). The positive animals for nematodes by floatation technique was subjected to McMaster technique and were classified based on the male $(67.3 \%)$ regarding sex categories and higher prevalence of gastrointestinal parasites was observed in untreated (86.3\%) animals than in treated $(34.1 \%)$ group. A statistically significant difference $(\mathrm{P}<0.05)$ was observed in sex category and in a group of treatment history. Higher prevalence was recorded in sheep with poor body condition $(77.4 \%)$ followed by medium body condition score $(77 \%)$ whereas the lowest prevalence was recorded in good $(71.25 \%)$ body condition score. However, there was no statistically significant difference $(\mathrm{P}>0.05)$ among black head sheep of different age and body condition score (Table 1). 
$[8,20]$ where the prevalence was $90.9 \%$ in sheep around Gondar, northern Ethiopia. Similarly, a higher prevalence was reported by Regassa et al. [21] with a rate of $94.1 \%$ in sheep of Mendayo district of Bale, southeast Ethiopia.

In the bases of sex categories, the finding reveals that the prevalence of gastrointestinal nematodes was higher in a female with a rate of $77.4 \%$ as compared to a male that found to be $67.3 \%$. The present study shows statistically significant differences $(\mathrm{P}<$ 0.05 ) between different sex groups. This indicated that male and female sheep of small ruminants had an unequal degree of infection because pastoralist encourages female as perpetuation purpose. There was a high number of the female herd that exposed to the same contaminated communal grazing pasture. Furthermore, sex was a determinant factor influencing the prevalence of parasitism and females were more prone to parasitism during pregnancy and per-parturient period due to stress and decreased immune status. The current finding agreed with that of Keyyu \& Regassa et al. [21,22] who indicated that gastrointestinal helminthes affect female sex groups differently. The current finding also agrees with Shimelis et al. [23] who reported a relatively higher prevalence of gastrointestinal nematode in female sheep as compared to male. This may be due to the presence of different risk factors such as; gestation stress, pre-parturient parasitic rise as the predisposing factors for higher prevalence in female stock. The female sheep generally harbored as a significantly higher worm burden than male sheep due to the enhanced grazing of females during lactation and their low resistance during pregnancy and parturition. In contrast to the present study, Mushtaq and Tasawr [24] observed a higher prevalence of gastrointestinal nematode in male $81.4 \%$ as compared to female sheep $73.1 \%$.

In the present study, the prevalence of nematodiasis was insignificant $(\mathrm{P}>0.05)$ in adult animals (76.9\%) compared with young animals (70\%). This disagrees with the report of Yimer et al. [25] who reported a significant association between the categories of age. The current study also revealed that the body condition score had no significant relationship $(\mathrm{P}>0.05)$ with GIT nematodiasis within good, medium and poor body condition sheep. The study further revealed that sheep with medium and poor body condition score had a higher prevalence rate of nematodiasis infection which was consistent with the previous report by Nigatu [26]. This might be due to either well-fed sheep have good immunity to resist parasitic infection which leads to an immunological response to the fecundity of the nematode.

\section{Conclusion and Recommendations}

The current finding suggested that gastrointestinal nematodes in black head sheep were highly prevalent in the study area. Infections of nematodes in black head sheep cause economic losses from decreased productivity as the majority of them harbored parasitism and because of the high load of strongly egg in sheep. Thus, the strategic wet-season deworming in the area was effective regarding prevention and control of parasitic infection. However, the most effective strategies to control the parasites are usually those based on a thorough knowledge of the species of parasites present, their seasonal availability and of the weather conditions in a particular area. On these bases, it is recommended that further studies should be conducted on the economic importance of nematodiasis in sheep in the study area for the successful implementation of nematodes control. Because of the high levels of pasture infectivity and worm burdens in sheep during the rainy seasons in the current study area, the sheep should be dewormed soon after the onset of rains and during the intervening dry season, monitoring the levels of infection in the sheep should is recommended.

\section{Acknowledgment}

The authors would like to acknowledge Yabello Regional Veterinary Laboratory for provisions of materials and facilities required to conduct this study.

\section{References}

1. CSA (Central Statistical Agency) (2012) Federal Democratic Republic of Ethiopia Agricultural Sample Survey. Volume II report on livestock and livestock characteristics (private peasant holdings), Addis Ababa, Ethiopia.

2. ILCA (International livestock center for Africa) (1990) Annual report program high lands, ILCA Addis Ababa, Ethiopia.

3. MOA (1998) The role of village dairy cooperatives in dairy development: prospective for improving dairy in Ethiopia. Paper presented at SDDP workshop held in Addis Ababa, Ethiopia, p. 4-7.

4. IIRR (1996) Ethnoveterinary medicine in Kenya. Field manual of traditional animal health care, pp. 115-116.

5. FAO (1974) Pakistan Livestock Sector Survey Report No. 32/74/Pak/7. FAO/World Bank Cooperative Programme p. 11.

6. Gilleard J (2006) Understanding anthelmintic resistance: the need for genomics and genetics. Int J Parasitol 36(12): 1227-1239.

7. Anon (2000) Small Ruminant Research Strategy. Ethiopian Agricultural Research Organization (EARO) Animal Science Research Directorate, Addis Ababa, Ethiopia, p. 40.

8. Perry B, Randolph T, Dermott J Sones K, Thornton P (2002) Investing in animal health research to alleviate poverty. International Livestock Research Institute (ILRI), Nairobi, Kenya, pp. 148.

9. Mucahy G, Neill SO, Ponnely S, Dalton JP (2004) Helminthes at mucosal barriers interaction with the immune system. 159: 593-598.

10. Waller PJ, Thramsborg SM (2004) Nematode control in green ruminant production systems. Trends in Parasitology 20(10): 493-497.

11. Bekele M, Feseha G, Shibru T (1982) Survey of gastrointestinal tract helminthes of sheep slaughtered at Addis Ababa abattoir, Ethiopia. Ethio J Agri Sci 4: 87- 94.

12. Teklay B (1991) Epidemiology of Endoparasites of Small Ruminants in Sub-saharan Africa. Proceedings of Fourth international Livestock Improvement Conference proceeding, in IAR Proceeding, 13-15, November 1991. Addis Ababa, Ethiopia, p. 7-15.

13. ORS (2004) The Oromiya Regional state government socio-economic profiles of Borana Zone, p.1- 97.

14. Thrusfield M (2005) Veterinary Epidemiology, (2 $2^{\text {nd }}$ edn), Blackwell Science, UK, pp. 180-181.

15. Soulsby EJL (1982) Helminths, Arthropods, and Protozoa of the domesticated animal. ( $7^{\text {th }}$ edn), Bailliere Tindall, London, Britain, UK, pp. 579-624. 
16. Urquhart GM, Armour J, Duncan JL, Dunn AM, Jennings FW (1996) Veterinary Parasitology, Second Edition, Blackwell Science, and the UK, pp. 257-276.

17. Taylor MA, Coop RL, Wall RL (2007) Veterinary Parasitology. (3 ${ }^{\text {rd }}$ edn), Blackwell Publishing Ltd, UK, pp. 195-197.

18. Kassa B (2005) Standard veterinary laboratory diagnostic manual Ministry of Agriculture and rural development Animal health department. Parasitology, 3: 34-40.

19. Lemma D, Biruhtesfa A, Surafel K (2015) Prevalence of Gastrointestinal Nematodes of small Ruminants and Around Arsi Negele Town, Ethiopia. Am-Euras J Sci Res 10(3): 121-125

20. Dagnachew S, Amamute A, Temesgen W (2011) Epidemiology of gastrointestinal helminthiasis of small ruminants in selected sites of North Gondar zone, Northwest Ethiopia. Ethiopian Veterinarian Journal 15 57-68.

21. Regassa F, Teshale S, Reta D, Yosef K (2006) Epidemiology of gastrointestinal parasites of ruminants in western Oromia, Ethiopia. Interna- tional Journal of Applied Research Institute Veterinary Medicine 4(1): 51-57.

22. Keyyu J, Kassuku A, Msalilwa L, Monrad J, Kyusgaard N (2006) Cross-sectional prevalence of helminth infections in cattle on traditional, small scale and large-scale dairy farms in Iringa district, Tanzania Veterinary Research Communications 30: 45-55.

23. Shemelis D, Asmare A, Wudu T (2011) Epidemiology of gastrointestinal helminthiasis of small ruminants in selected sites of North GondarNorthwest Zone Ethiopia. Ethio Vet J 15: 57-68.

24. Mushtaq HL, Tasawar Z (2011) Prevalence of some gastrointestinal parasites in sheep in southern Punjab, Pakistan. Pak Vet J 31: 295-298.

25. Yimer A, Dessalegn S, Shahid N (2016) Prevalence and associated risk factors of gastrointestinal nematodiasis in small ruminants in northeast Ethiopia. Journal of Animal Research 6(2): 165-170.

26. Nigatu K (2008) Gastrointestinal Helminthiasis of Sheep in Awi Zone, northwestern Ethiopia. Global Veterinarian 12: 121-129.

This work is licensed under Creative

Commons Attribution 4.0 License

DOI: 10.19080/JDVS.2019.11.555813

Your next submission with Juniper Publishers
will reach you the below assets
- Quality Editorial service
- Swift Peer Review
- Reprints availability
- E-prints Service
- Manuscript Podcast for convenient understanding
- Global attainment for your research
- Manuscript accessibility in different formats
( Pdf, E-pub, Full Text, Audio)
- Unceasing customer service
Track the below URL for one-step submission
https://juniperpublishers.com/online-submission.php

